\title{
Edgar Bernad-Mechó* \\ Metadiscourse and Topic Introductions in an Academic Lecture: A Multimodal Insight
}

\author{
DOI 10.1515/mc-2016-0030
}

\begin{abstract}
This paper is part of a larger scale project where I explore the structure of academic lecture. The focus of the study here presented is to investigate the structure and organization of a university lecture through the introduction of new topics. One of the tools traditionally referred to as an organizer of discourse is metadiscourse (Crismore et al. 1993. Metadiscourse in persuasive writing: A study of texts written by American and Finnish university students. Written Communication, 10:39-71; Vande Kopple. 1985. Some exploratory discourse on metadiscourse. College Composition and Communication, 36(1):82-93). Although metadiscourse has been studied from a wide range of perspectives (Hyland. 2005. Metadiscourse: exploring interaction in writing. London, England: Continuum), these analyses have most of the time been conducted from a purely linguistic point of view and neither the speaker as a social actor nor metadiscourse as part of a multimodal interaction are taken into account. That being so, the aim of this study is to explore the role played by introducing topic metadiscourse (Ädel. 2010. Just to give you kind of a map of where we are going: a taxonomy of metadiscourse in spoken and written academic English. Nordic Journal of English Studies, 9 (2):69-97) from a multimodal perspective as it is being used within a lecture. In order to obtain a holistic account on how topics are introduced and the role of metadiscourse within the set of actions performed by the speaker in interaction, I make use of the tools provided by Multimodal (Inter)action Analysis (Norris. 2004. Analyzing multimodal interaction. A methodological framework. New York: Routledge; 2011. Indentity in (Inter)Action. Introducing multimodal interaction analysis. Göttingen: De Gruyter Mouton). The main analysis is carried out on two excerpts where new topics are being introduced which come from a lecture on African-American History belonging to Yale University's opencourseware. Through the production of verbal and multimodal transcripts, this paper demonstrates how the lecturer structures the class before he verbally utters metadiscursive expressions and the minor significance that these instances play in the lecturer's broad organization of the lecture, as metadiscourse is predominantly performed as a background task.
\end{abstract}

Keywords: Multimodal (Inter)action Analysis, metadiscourse, introducing topic, spoken academic lectures

\section{Introduction}

The present paper reports on one part of a large-scale investigation of the use of organizational metadiscourse in academic lectures across different disciplines and lecturing styles. The small-scale study here presented investigates how a conversational-style lecturer introduces new topics in one university lecture and the role metadiscourse plays in the set of actions he performs. Metadiscourse, commonly referred to as "discourse about discourse" (Vande Kopple 1985:83), is defined as a tool employed by writers (and speakers) to guide readers (and listeners) through the discourse, to achieve a greater connection with them and organize ideas (Crismore et al. 1993; Hyland 2005; Vande Kopple 1985), thus showing a certain degree of reflexivity upon the discourse (Ädel 2006, 2010; Mauranen 1993b).

University lectures are complex genres that involve intricate interactions between lecturers and students. Swales (1990:58) defines genre as "a class of communicative events, the members of which share some set of communicative purposes". In the case of academic lectures as a genre, there is an ongoing discussion as to whether academic lectures should be considered single or multiple genres. For example, Duff (2010) argues that multiple genres like narrative or dialogue may be found within academic lectures.

*Corresponding author: Edgar Bernad-Mechó, Universitat Jaume I (UJI), Castelló de la Plana, Spain, E-mail: ebernad@uji.es 
Nevertheless, and in order to simplify this study, I refer to academic lectures as a single genre encompassing the whole process of lecturing.

As I mentioned above, I set out to investigate the how a professor organizes a lecture through the use of organizational metadiscourse in the introduction of new topics. Organizing and structuring lectures are crucial issues new lecturers have to face in their first encounters with university education (McKeachie and Svinicki 2013; Nilson 2016). Furthermore, the introduction of topics sets the foundation to keep audience interest and smooths the path for the students to comprehend the new ideas (Palmer Silveira 2004). In this paper, I pay special attention to the role of introducing topic metadiscourse (Ädel 2010) as a device commonly used by lecturers as a tool that helps organize the discourse (Crismore et al. 1993; Vande Kopple 1985).

With the aim of examining how topics are introduced and how metadiscourse is used, I make use of the concepts of lower and higher-level actions, modal density, foreground-background continuum and semantic/ pragmatic means provided by Multimodal (Inter)action Analysis (MIA) (Norris 2004, 2011). By using this approach, I investigate topic introductions as part of the interactions carried out by the lecturer and taking into account human communication as a whole entity made up of series of actions. This opposes traditional linguistic studies on metadiscourse where metadiscourse is analyzed from a linguistic point of view disregarding the ways in which social actors use metadiscourse and the roles metadiscourse plays within the set of actions performed by social actors.

Multimodal approaches in the field of higher education have increased in recent years. For instance, Fox and Artemeva (2013) explore the multimodality of 'chalk-talk' in mathematics lectures; Bannink and Van Dam (2013) look into discursive uses that generate student involvement in 'first lectures'; and especially Crawford-Camiciottoli and Fortanet-Gómez (2015) compile a series of multimodal studies into conference presentations and academic lectures. Nevertheless, and despite this amount of work, multimodal insights into university lectures are still scarce and further research is needed in order to better understand the complexity of this genre.

All in all, this article shows how metadiscourse is employed as part of mid-grounded actions most of the time serving either as a transitional resource from one topic to another or as a filler to keep the verbal flow going while the speaker performs other foregrounded actions. Moreover, the analysis demonstrates that the lecturer structures his interaction through higher-level actions separated by semantic/pragmatic means before he verbally produces metadiscursive expressions. Consequently, metadiscourse is not primarily utilized to organize discourse, hence contradicting most traditional definitions of the term. Finally, the study indicates the presence of two broad types of interactions in the lecturer: those which are notedriven and those which are spontaneous. In the analyses here presented, the former type of interaction receives higher attention from the lecturer. As a result, I argue that notes as a mediational means become significant in the social actor's lecturing process.

In the following sections I review some literature on the relevance of topic introductions and consider how metadiscourse can be used in the introduction of topics. Then, I move on to a description of the methodological concepts from MIA that are used in this study and I define the dataset utilized and processes followed. Finally, I show two excerpts from a university lecture where new topics are introduced and carry out a multimodal analysis to illustrate the role of metadiscourse within the communicative action.

\section{Introducing topic}

Introducing the topic is one of the key elements within a lecture as it provides the audience with information regarding the main topic and concepts, as well as the purpose of the lecture (Palmer Silveira 2004). Young (1994) includes topic introduction within discourse structuring phases where lecturers show the direction they are following in their lectures. The importance of these phases lies in their role in easing comprehension for the students. In a previous work, Young (1990) reflects upon the importance of discourse structuring phases and argues that "the lecturer explicitly involves the students in the unfolding of the 
information, thereby ensuring that the audience is aware of the nature of the activity in which they are both engaged" (Young 1990:85). Moreover, Palmer Silveira (2002) provides a series of variables to be considered when delivering a lecture. These include the organization of the material in an easy way for the audience to understand and the clear articulation of the purposes and the topics of the lectures. In a corpus-driven study, Palmer Silveira (2004) examines thirty lectures in business, law and sociology and establishes four trends in which topics are introduced:

a) explicitly introducing the topic followed by an occasional outline of the lecture

b) explicitly introducing the topic by using some references to previously acquired knowledge

c) introducing the topic through an example

d) introducing the topic through the use of a humorous remark

Palmer Silveira's results show that types a) and b) seem to be the most common ones in the lectures observed, leaving types c) and d) as infrequent. In addition, types a) and b) include an explicit reference to the introduction of the topic and consequently, a certain degree of reflection upon the process of lecturing. These levels of reflexivity as well as the explicit introduction of the topic can be regarded as being metadiscursive utterances.

\section{Metadiscourse}

The analyses in this paper focus on how metadiscourse is used in the introduction of topics. Metadiscourse has been studied from many different perspectives in many distinct disciplines and languages (Hyland 2005). Two broad perspectives towards the analysis of metadiscourse can be identified: the interactive (or integrative) and the reflexive (or non-integrative) approaches. The interactive approach (Crismore et al. 1993; Hyland and Tse 2004; Vande Kopple 1985) is based on Halliday's (1973) theory of the functions of language (ideational, interpersonal and textual functions). The interactive perspective identifies metadiscourse with all non-propositional material, i.e. with the interpersonal and textual functions. These approaches are in conflict with one another when defining and delimiting what can be considered metadiscourse. The main issue lies in what is considered metadiscourse and is not and the criticism comes from the fact that interactive approaches seem to be "too all-inclusive" (Ädel 2006:171) encompassing categories like stance/evaluation as metadiscourse. In order to overcome this problem, reflexive approaches (Ädel 2006, 2010; Mao 1993; Mauranen 1993a, 1993b) rely on the reflexivity of the language as fundamental for metadiscourse to be considered as such. Ädel's $(2005,2006,2010)$ reflexive perspective on metadiscourse is based on Jakobson's $(1960,1998)$ theory of the six functions of language. She identifies the metalinguistic function with reflexivity upon the text/code, the expressive function with the reader (or listener) and the directive function with the writer (or speaker). Then, Ädel establishes two broad categories of metadiscourse: metatext that shows how texts (or speeches) are organized, and writer-reader interaction for references that acknowledge the present of the writer (or speaker) and the reader (or listener) (Ädel 2006).

Despite the differences between both approaches, the organization of texts as a function carried out by metadiscourse is one of the key common elements included in most approaches regardless of the paradigm employed. Vande Kopple (1985) talks about text connectives whose function is that of organizing texts and guiding readers through sequencers, logical or temporal connectives, reminders, announcements and topicalizers. Topicalizers are particularly relevant for the purposes of this paper, as I set out to investigate how topics are introduced. Topicalizers are also included in Crismore, Markkanen, and Steffensen's (1993) taxonomy, in Hyland's (2005) under the label of frame markers and in Ädel's $(2006,2010)$ as introducing topic.

In the present study, I utilize Ädel's (2010) taxonomy of metadiscourse (see Table 1 below for a summary and a list of examples). Ädel's approach arises from a corpus analysis in which she examines 30 spoken academic lectures and 130 essays, thus restricting her focus to academic language. To my knowledge, Ädel's is the only reflexive approach that thoroughly considers spoken academic English. 
Table 1: Adapted from Ädel's (2010) taxonomy of metadiscourse in academic English.

\begin{tabular}{|c|c|}
\hline Type of metadiscourse & Example \\
\hline \multicolumn{2}{|l|}{ Metatext } \\
\hline \multicolumn{2}{|l|}{ Metalinguistic comment } \\
\hline Repairing & I'm sorry, that's not correct. \\
\hline Reformulating & Let me put it in other words... \\
\hline Commenting on linguistic form/meaning & I'm not sure how to say this, but... \\
\hline Clarifying & Now, I'm not saying that is the case, what I mean is that... \\
\hline Managing terminology & Let's take a look at what metadiscourse means. \\
\hline \multicolumn{2}{|l|}{ Discourse organization } \\
\hline Introducing topic & Today I want to talk about the American Revolution. \\
\hline Delimiting topic & We won't go into that in this class. \\
\hline Adding to topic & Let me add to that that, it was not until 1785 that... \\
\hline Concluding topic & Now, we've seen how Americans became independent and how... \\
\hline Marking asides & I want to do an aside here... \\
\hline Enumerating & There are two aspects you should know about; first ... (...) and second... \\
\hline Endophoric marking & Please look at page 373 from your book. \\
\hline Previewing & We'll talk about that in our class next week. \\
\hline Reviewing & Last lecture I talked about... \\
\hline Contextualizing & I believe I still have a couple of minutes to talk about this. \\
\hline \multicolumn{2}{|l|}{ Speech act labels } \\
\hline Arguing & I will argue that they did not plan it like that. \\
\hline Exemplifying & Let me give you an example of that... \\
\hline Other speech act labeling & I want to remind you that... \\
\hline \multicolumn{2}{|l|}{ Audience interaction } \\
\hline \multicolumn{2}{|l|}{ References to the audience } \\
\hline Managing comprehension/channel & Can you hear me back there? \\
\hline Managing audience discipline & May I have your attention, please? \\
\hline Anticipating the audience's response & You'll probably think that I am wrong... \\
\hline Managing the message & What I want you to think about is how all these elements... \\
\hline Imagining scenarios & Now, imagine you have to do that. \\
\hline
\end{tabular}

Moreover, the use of a reflexive approach opens up the possibility of a more qualitative study (Ädel and Mauranen 2010) since metadiscourse is considered in its context, which allows for a more comprehensive understanding of how it works. Finally, the study of organizational metadiscourse as it is being used in an academic lecture will shed light on the process of organizing and structuring lectures and could further be applied to the training of new lecturers.

The study of metadiscourse has been particularly relevant in spoken academic genres in general, and academic lectures in particular. Crawford-Camiciottoli (2004), for instance, compares the use of interactive discourse structuring in guest lectures (English as L1 and L2) to non-native speakers and classroom lectures (English as L1) to mostly native speakers. In another study, Lee and Subtirelu (2015) make use of Hyland's (2005) model to examine the metadiscourse employed by native English speakers in content university lectures for native speakers and English for Academic Purposes lessons for nonnative speakers. In addition, multimodal studies on academic lectures are currently receiving growing attention (Crawford-Camiciottoli and Fortanet-Gómez 2015; Fortanet-Gómez and Ruiz-Madrid 2015, 2016; Fox and Artemeva 2013; Ruiz-Madrid and Fortanet-Gómez 2015, 2016; Thesen 2016). As far as metadiscourse from a multimodal perspective is concerned, Thompson (2003), for example, compares the use of text-structuring metadiscourse in university lectures and English for Academic Purposes published listening materials while also analyzing the role of intonation as a resource to structure lectures. Furthermore, in Bernad-Mechó and Fortanet-Gómez (2017) we compare the use of gestures in the use of organizational metadiscourse in two lectures in English and two in Spanish. However, the study of how metadiscourse is used mostly been restricted to purely linguistic point of views, and multimodal 
approaches to metadiscourse are scarce. In this sense, further research to examine the relationship between metadiscourse and the speaker is needed. In the following section I describe the methodology employed for this study.

\section{Methodology}

MIA (Norris 2004, 2011) is grounded in mediated discourse analysis and the concept of mediated action (Scollon 1998, 2001). A mediated action refers to a social actor acting through or with mediational means (Scollon 1998). MIA allows for an in depth exploration of human communication providing a holistic perspective. In the present study, a MIA approach provides further insight into the complex process of lecturing by focusing on the actions carried out by the lecturer. Taking the mediated action as its unit of analysis, MIA distinguishes three types of actions: lower-level actions, higherlevel actions and frozen actions. Out of these, lower and higher-level actions are especially relevant for this study.

A lower-level action is defined as "the smallest interactional meaning unit" (Norris 2004:11). For example, a posture change, a gesture or an utterance could be lower-level actions. Lower-level actions are demarcated by a beginning and by an end. Higher-level actions, on the other hand, consist of chains of lower-level actions bracketed by an opening and a closing (Norris 2004). For example, talking about the weather could be a higher-level action formed by a series of lower-level actions including many utterances, gestures, gaze shifts, etc. These higher-level actions in turn can often be sub-divided into smaller higher-level actions or embedded within other higher-level actions. Thus, the higher level action of talking about the weather might be divided into smaller actions like discussing temperature and discussing the latest heavy rains; and it could be embedded within a hypothetical supra higher-level action of meeting with friends. Norris (2017) refers to this hierarchy of actions as scales of actions.

Another relevant concept within MIA is the foreground-background continuum (Norris 2004). Social actors producing higher-level actions may conduct several higher-level actions at the same time at different levels of attention/awareness. For instance, while a social actor is talking about the weather they may also be taking care of their children and thinking about dinner at the same time. The foreground-background continuum enables the representation of different levels of attention/awareness in a three-staged graph demonstrating the higher-level actions occurring in the foreground, midground and background. While several higher-level actions can occur in the social actor's midground (receiving a certain degree of attention) or in their background (barely being aware of the action), only one higher-level action can be foregrounded at the same time. Going back to the previous example, one can only be completely focused on either talking about the weather, taking care of children, or thinking about dinner, i. e. the action in the foreground. The other two actions, albeit simultaneous, will receive less attention by the social actor and will therefore be represented in the midground or background. Foregrounded higher-level actions are focused on higher-level actions, i. e. the social actor is highly aware of them and devotes most of their attention/awareness to its fulfillment.

The levels of attention/awareness of the social actor towards a higher-level action are determined by their modal density (Norris 2004). The concept of modal density arises from the concept of a mode. Norris (2013:156) defines mode as "a system of mediated action with regularities" and so, modes are acquired by the users as they interact through lower-level actions in the world. Nevertheless, Norris understands modes as theoretical constructs that assist the researcher in their analyses since they help to dissect communication as a whole into smaller distinguishable aspects. According to Norris, the regularities of the modes are sometimes closer to the social actor and sometimes closer to the mediational means, but modes do not occur without the social actor. Consequently, the focus of the study is on how the speakers act, and how these actions depend on the modal development (Norris 2013). In the 
case of this paper, for example, I analyze the modes of spoken language (and its intonation), gesture, posture and gaze.

Modal density is determined by the complexity and/or the intensity of modes. Thus, a higher-level action is more modally dense when the action is produced with higher modal complexity (many modes devoted to carry out the action), or when it is produced with a higher modal intensity (a given mode or modes take a more intense role in the performance of the action). In other words, if a social actor is, for instance, talking about the weather while their posture and gaze are turned towards their interlocutor and their gestures are related to the conversation, the action is modally complex, as most modes are devoted to the performance of the action. However, if the social actor is engaged in talking about the weather but suddenly turns their head to a kid and says "stop doing that", then the higher-level action of taking care of children becomes modally dense after receiving high modal complexity (most modes are still devoted to the action of talking about the weather but the modes of gaze and spoken language play a more intense role).

Finally, the last concept that I will focus on is that of semantic/pragmatic means (Norris 2004). Higherlevel actions are produced with different levels of attention/awareness all the time, being foregrounded, midgrounded or backgrounded constantly. Shifts when foregrounding higher-level actions are frequently indicated by a semantic/pragmatic means. Semantic/pragmatic means are pronounced lower-level actions (e. g. a gesture, a head movement, laughter, etc.) that indicate a shift in the level of attention that a social actor devotes to particular higher-level actions. They carry out two functions: a semantic function, as they structure the social actor's interaction organizing foregrounded higher-level actions; and a pragmatic function, as they can communicate the social actor's shift to the interlocutors.

\section{The data}

The main objective of this paper is to investigate the role of introducing topic metadiscourse (Ädel 2010) in an academic lecture within the set of higher-level actions performed by the lecturer. The data for this study consists of two short excerpts where introducing metadiscourse is used, extracted from a lecture on African American History taught at Yale University. This lecture belongs to the opencourseware of Yale University (Open Yale Courses) and it is accessible on-line at http://oyc.yale.edu. The lecture is taught by Prof. John Holloway, who could be defined as taking a conversational lecturing style following Dudley-Evans's (1994) classification of lecturing styles. Conversational style lecturers are characterized by using notes when lecturing but in a conversational manner, i. e. not reading through them.

In the following section, I explore these two excerpts through a verbal and multimodal transcription and a thorough multimodal analysis utilizing the concepts of lower and higher-level actions, modal density, foreground-background continuum and semantic/pragmatic means. In order to conduct a multimodal analysis, I make use of relevant screenshots selected from the video files which show how the different modes are used. As aforementioned, I explore spoken language (and its intonation), gestures, gaze and posture in this paper. In the case of gaze and posture, only shifts in position and gaze direction are identified. On the other hand, and although the analysis of gestures is not the main aim of this paper, it is worth mentioning that I make use of McNeill's (1992) terminology for gestures. According to McNeill, gestures are iconic when there is a relationship with the semantic content of speech; metaphoric when there is a pictorial relationship but they present abstract ideas; beats if the same gesture is used repeatedly as marking the rhythm of speech; or deictic if they point at something concrete or abstract. Finally, a particular interest is placed on the use of prosody. In the representation of intonation, I utilize the software Sonic Visualiser (Cannam et al. 2010) together with the algorithm pYin (Mauch et al. 2015; Mauch and Dixon 2014). The algorithm pYin is able to create estimated pitch lines out of monophonic sources, thus achieving a working depiction of intonation that becomes highly functional in multimodal analyses. As shown in Figures 1 and 5 below, the intonation line created with pYin displays rising and falling tones as well as intensity peaks. 


\section{Analysis}

\section{Excerpt 1}

Excerpt 1 takes place 8 minutes into the lecture. In this excerpt, the lecturer concludes his introduction by listing topics dealt with in the previous lecture. The lecturer then introduces a new topic, the Fair Employment Practices Commission (FEPC), which links to a lecturing section on the topic. He introduces the topic of the FEPC through the use of introducing topic metadiscourse. Transcript 1 shows the mode of spoken language of the excerpt. The lecturer, Prof. Holloway, reviews previous topics, introduces a topic by using metadiscourse (08:21:12 to 08:27:16) and starts lecturing on the introduced topic.
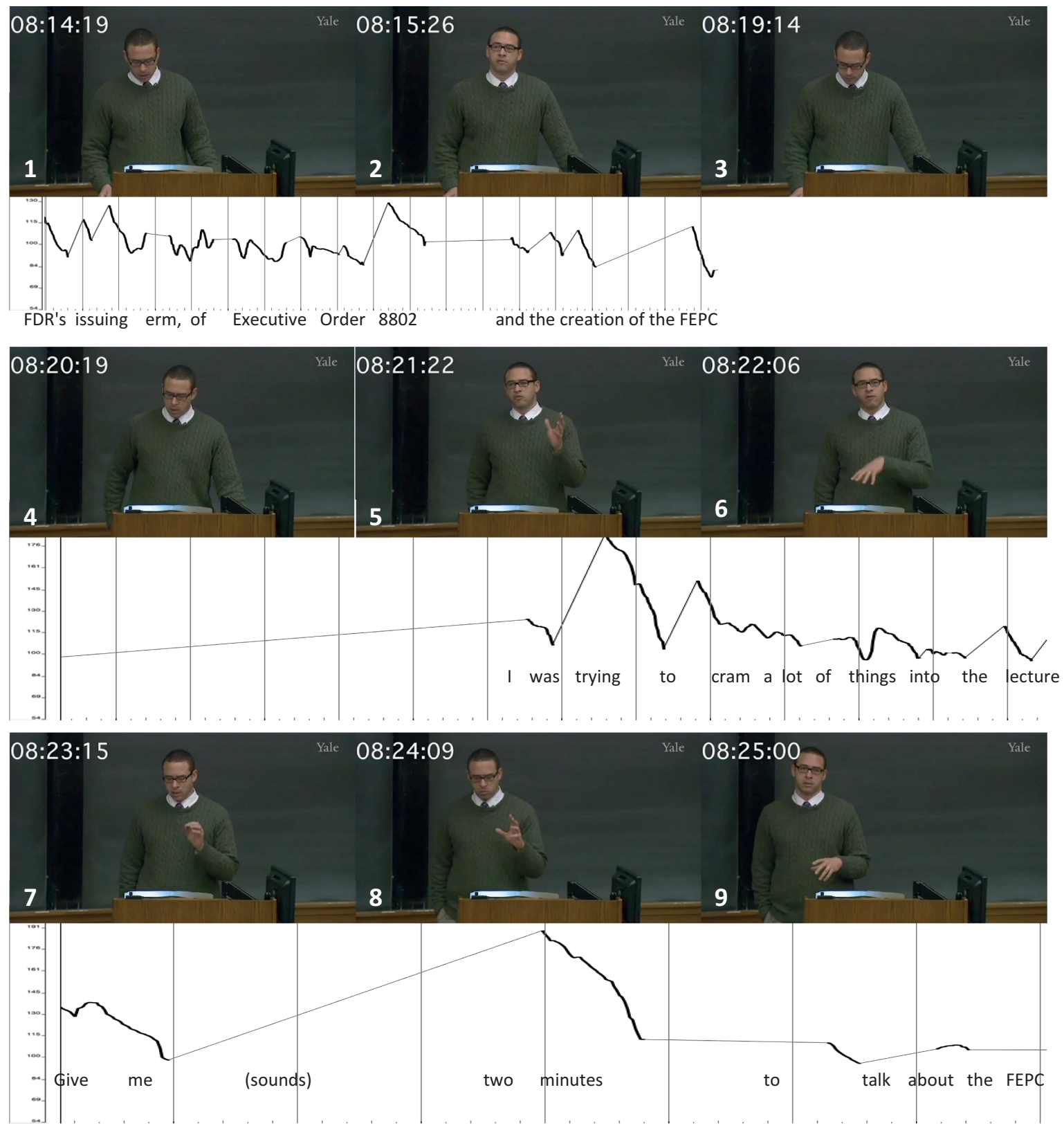

Figure 1: (a) Multimodal transcription of Excerpt 1. 

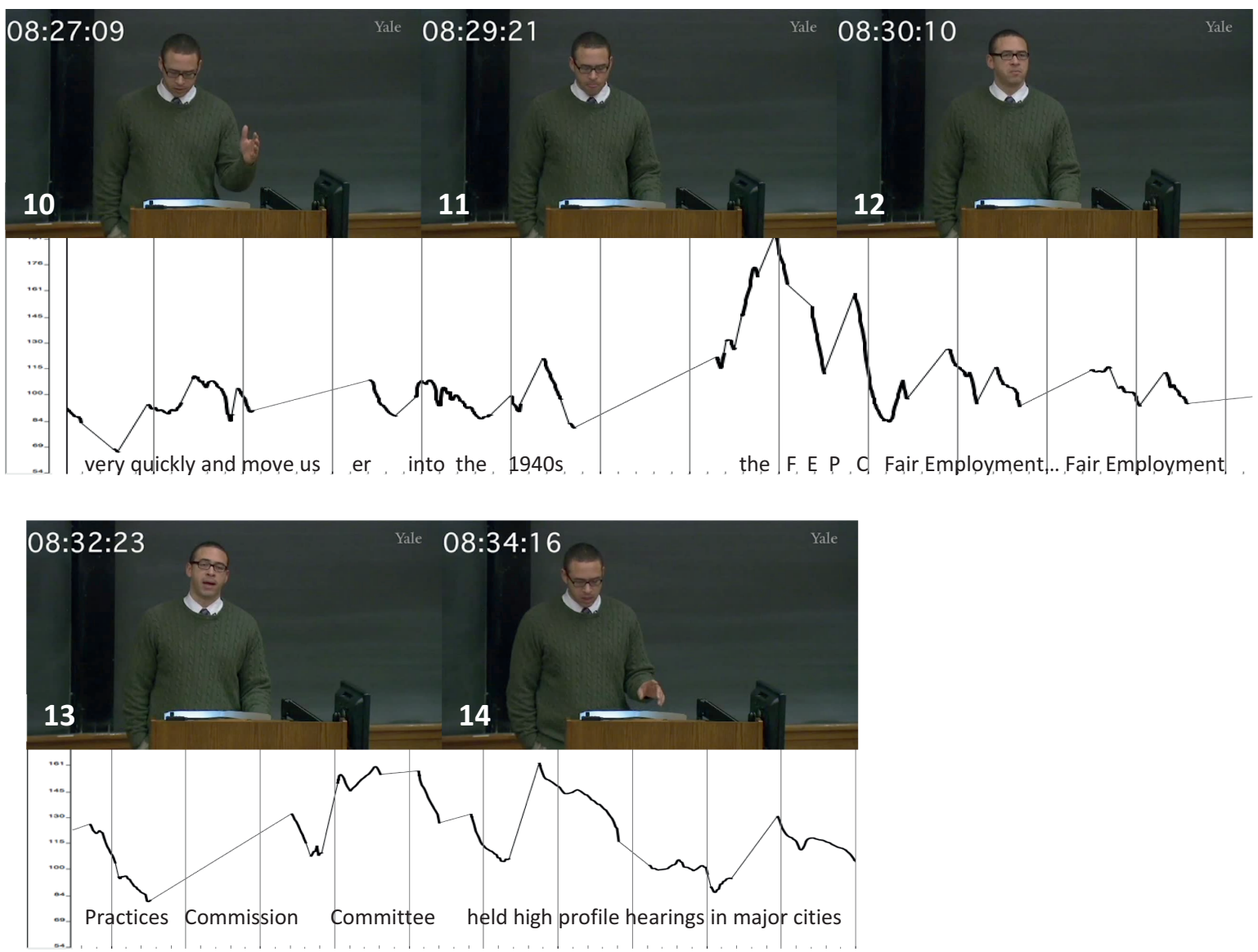

Figure 1: (b) Multimodal transcription of Excerpt 1.

Transcript 1: introducing topic "FEPC"

08:14:07 FDR's issuing

erm

of Executive Order 8802

08:17:16 and the creation of the FEPC

08:21:12 I was trying to cram a lot of things into the lecture $\bigsqcup_{\text {give me }}$

08:23:25 (sounds)

08:24:05 two minutes to talk about the FEPC very quickly and move us

08:27:16 um...

into the 1940s

08:29:25 the FEPC

08:31:03 Fair Employment --

08:31:27 Fair Employment Practices Commission Committee

08:34:25 held high profile hearings in major cities 
Figure 1 shows a multimodal transcription of this excerpt. This excerpt is selected as it shows three different higher-level actions performed when moving from the introduction of the lecture to a new topic. The excerpt begins with Prof. Holloway reviewing the topics dealt with in the previous lecture through an enumeration as he utters the phrase "FDR's issuing, erm, of Executive" (Image 1). He leans on his notes while gazing at them and resting both hands on the lectern. He then finishes the sentence "Order 8802" (Image 2) with a rising pitch intonation, which commonly indicates that there is more information coming up. Although he gazes at his notes most of the time, he also produces a quick gaze shift towards the audience (Image 2). He then continues with "and the creation of the FEPC" with a falling pitch intonation at the end followed by a pause, which indicates that the enumeration has come to an end. Next, he leans on the lectern in a seemingly comfortable posture, as he lowers his shoulders (Image 3) and performs a slight mouth movement. He moves his right hand and puts it in his pocket (Image 4). Then, he turns his head and body towards the audience and rushes through the phrase "I was trying to cram a lot of things into the lecture" with a short syllabic duration. At the same time he moves his left hand from an upper position (Image 5) towards his notes (Image 6), producing a deictic gesture and holding the final position for a full second. Latched to the previous utterance, Prof. Holloway says "Give me..." while raising his right hand from the lectern and joining his thumb and index fingers (Image 7). After this, he pauses briefly and continues "two minutes" while slightly opening his fingers (Image 8).

At this point he starts performing a slight swaying movement with his upper body and turns his gaze to the audience. Next, he holds his hand above the lectern as he turns his body to an upright position and continues the sentence "to talk about the FEPC" (Image 9). He finishes the sentence "very quickly and move us, um, into the 1940s" while turning his gaze to his notes and leaning forward (Image 10). He produces this sentence with a falling pitch at the end followed by a pause that indicates the end of the utterance. At the same time, he moves his open left hand from a central position to his left. Then, he moves the hand to the lectern and stops his swaying movement (Image 11). He positions his body in a more upright position and licks his lips. He then begins the utterance "The FEPC" together with five beats on the lectern. The lecturer shifts his gaze to the audience and starts lecturing on the new topic with some hesitation "Fair Employment ... Fair Employment" (Image 12) and correction "Practices Commission, Committee" (Image 13). He performs a quick glance to the audience and then turns his gaze back to his notes.

Next, he starts swaying again while slightly turning his body towards his notes (Image 14). Finally, he moves his left hand up and down in a small movement as he utters "held high profile hearings in major cities" with a relevant rising pitch ending, which indicates that the utterance is not finished.

The analysis shows that Prof. Holloway focuses on three different higher-level actions: concluding introduction, introducing topic and lecturing. The foreground/background continuum of attention/awareness shows these higher-level actions in three different moments within the excerpt as shown in Figures 2 and 3.

Figure 2 shows the first shift in focus in the higher-level actions during this excerpt. The graphs show higher-level actions (outer circles) and their modal density in the form of modes (inner circles) where their importance within the multimodal ensemble is related to the size of the circle. For the purposes of this study, I have focused on four modes that seem to play an important role in the interaction: gaze, posture, gestures, and spoken language. Moreover, I have included proxemics as one of the modes taking part in the modal ensemble. Even though the distance between the lecturer and his surroundings and the audience does not vary across the excerpts and so, it is not considered in the analyses, proxemics is indubitably one of the modes present in the interaction.

The higher-level action of concluding introduction is foregrounded at the beginning of the excerpt (Graph 1). High modal density is shown in the lecturer's posture and gaze towards his notes (Images 1 to 3 ) and his utterances enumerating previous content. Here, the analysis shows the lecturer engaging with his notes as he focuses on concluding his introduction. The rising intonation at the end of the utterances suggests that there is more information to be disclosed and therefore, the higher-level action continues.

Then, the lecturer stops swaying and the falling intonation used in "and the creation of the FEPC" (Image 2) indicates the ending of the higher-level action of concluding introduction. He shifts posture from a position orientated towards his notes to a more upright posture. The completion of the utterance "and the creation of the 
Modal

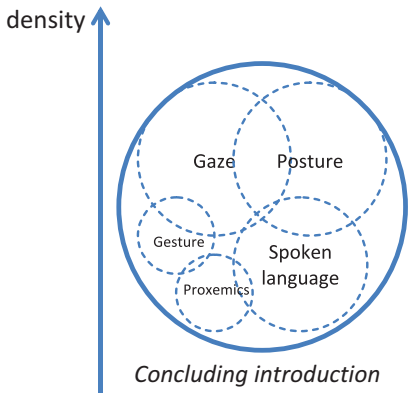

Foreground

odal

density

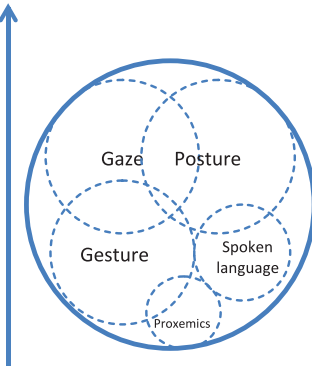

Introducing topic

Foreground
GRAPH 1

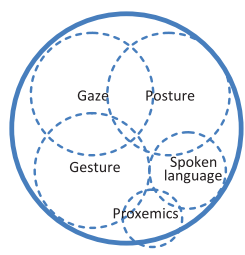

Introducing topic
Midground

GRAPH 2
Background

Decreasing

Attention/awareness

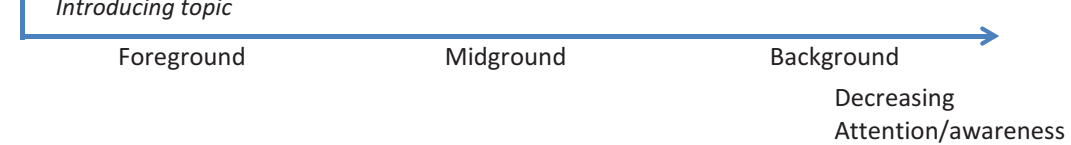

Figure 2: Shift in attention/awareness from concluding introduction to introducing topic.

FEPC" together with the subsequent change in posture show a shift in attention/awareness from the higherlevel action of concluding introduction towards the higher-level action of introducing topic (Graph 2).

The shift in focused on higher-level actions is marked by a semantic/pragmatic means (Images 4 and 5); the gesture performed with the lecturer's right hand is a pronounced lower-level action that does not fit in any of the higher-level actions previously described. The semantic/pragmatic means is a device employed by the lecturer to structure his own actions (the lecture) in his mind; in other words, it carries out a semantic function. The pragmatic function, i. e. the one of informing the audience of such a shift, however, does not seem to be of particular relevance in this case.

Graph 2 shows how the lecturer shifts his focus. Prof. Holloway now gazes mostly at the audience with occasional glances to his notes. His posture is more upright and open to the audience. These changes are particularly marked when compared with his posture and gaze in images 1 to 3 . The higher-level action of introducing a topic is foregrounded here, while concluding introduction has disappeared. While the higherlevel action of concluding introduction included significant interaction with notes, the higher-level action of introducing topic includes significant interaction with the audience. The interaction with the audience can be seen in the lecturer's posture and gaze as well as in the types of gestures employed. Graphs 1 and 2 show the modal density of both higher-level actions where posture and gaze play an important role in analyzing the focus of the lecturer. However, when going back to the transcript, different uses of these modes can be observed. As Prof Holloway produces the higher-level action of introducing the topic, his posture is opened up to the audience and the swaying that characterizes his lecturing has stopped. Moreover, his gaze is fully 
focused on the audience. In addition, his arm movements are much more spontaneous deictic gestures (images 5 to 10).

An increase in the intensity of the mode of gesture can also be seen in Graph 2, indicating a higher relevance of gestures to the meaning of the higher-level action. While beat gestures, as defined by McNeill (1992), consist of rhythmic up-and-down movements suggesting regular patterns that accompany prosody in the conversation, both deictic and metaphoric gestures convey much more meaning. They reflect to a greater or lesser extent the contents of the spoken language. Therefore, I argue that the deictic gestures present in the higher-level action of introducing topic are more relevant to this type of spontaneous interaction.

After the semantic/pragmatic means, the first higher-level action vanishes and will not come up again in the excerpt. The mode of spoken language becomes more spontaneous and natural, rather than a more artificial style constrained by the notes. The utterance right after the shift in attention/awareness ("I was trying to cram a lot of things into the lecture") is characterized by a reduced syllabic duration. Together with the changes in the modes of posture, gaze and gesture, this section shows a distinct modal density demonstrating a change in higher-level actions (images 5 and 6). Although it is not the main focus of this article, it is worth mentioning that the utterance "I was trying to cram a lot of things into the lecture" constitutes an instance of contextualizing metadiscourse (Ädel 2010). It shows high reflexivity upon the process of lecturing and hence its spontaneity. The utterance following this one ("Give me two minutes to talk about the FEPC") also belongs to the higher-level action of introducing topic and is produced immediately after the previous one.

In addition, the presence of another higher-level action in the mid-ground seems to exert some influence over the higher-level action of introducing topic. Figure 3 shows one further shift in attention by the lecturer.

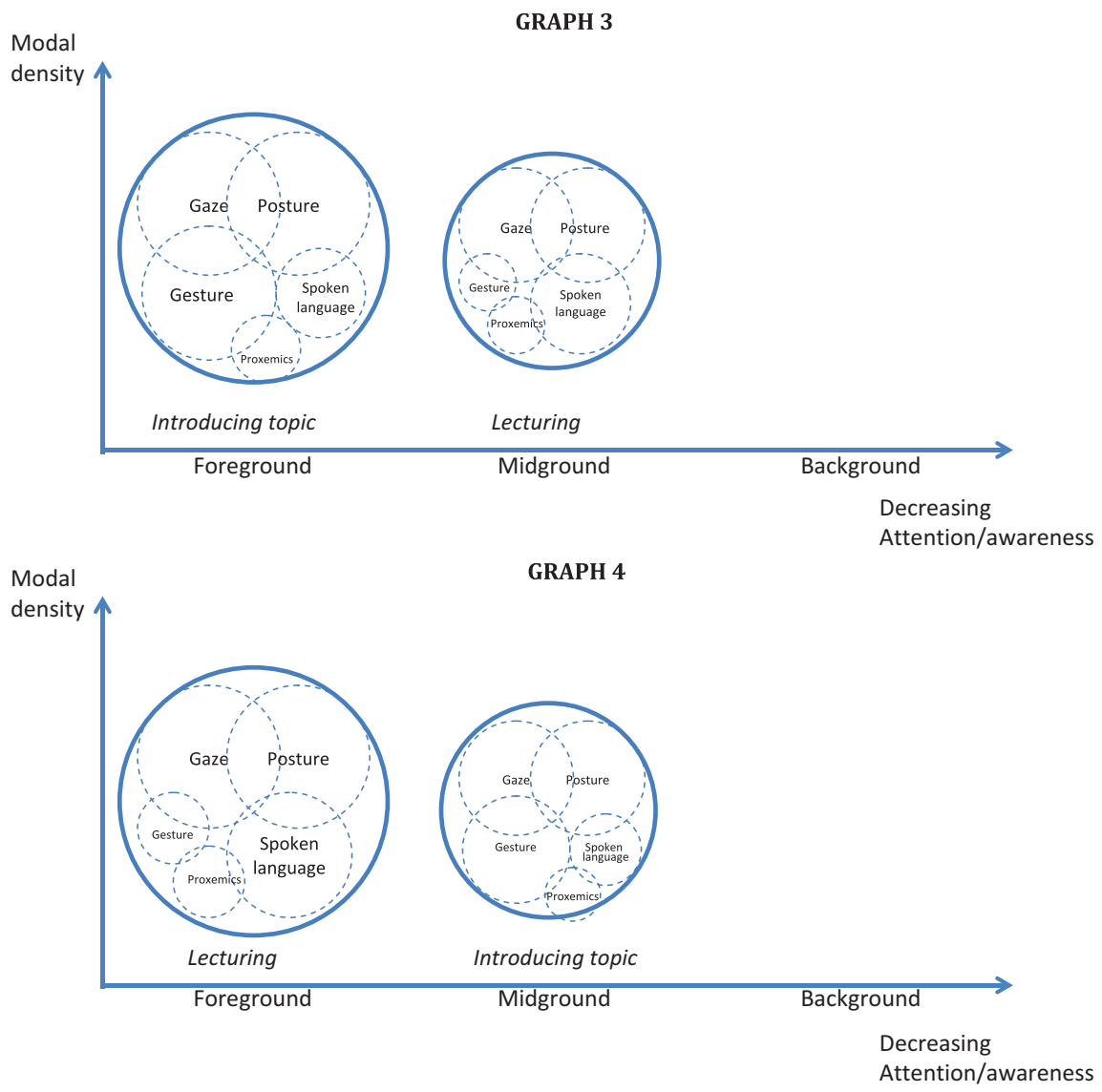

Figure 3: Shift in attention/awareness from introducing topic to lecturing. 
The lecturer's gaze and posture change to show the lecturer focusing on the notes for a moment as he starts a slight swaying movement (image 7). These lower-level actions are normally present in lecturing sections rather than in spontaneous comments; it seems that the higher-level action of lecturing is midgrounded in the foreground/background continuum as of this moment (Graph 3). The utterance "Give me two minutes to talk about the FEPC", unlike the previous utterance, is separated into chunks (images 7 to 9) probably due to a rising influence of his notes. In image 10 his gaze and posture turn back to his notes once again for a longer period of time and his swaying stops. This occurs while he concludes the introduction of the topic.

The lecturer's left hand then goes back to the lectern in what appears to be a second semantic/ pragmatic means followed by a short pause (image 11). He then begins lecturing on the new topic (image 12). At this point the higher-level action of introducing topic, characterized by being a spontaneous comment to the audience, shifts to a lower-level of attention/awareness while the modal density of the higher-level action of lecturing increases through the changes in gaze and posture (Graph 4).

Nevertheless, the modal density of the new higher-level action has not reached its peak yet. This occurs when a series of common patterns throughout the whole lecture begin to appear: a constant sequence of swaying and quiet position movements, gaze shifts from the notes to the audience with a regular focus on the notes (images 13 and 14) and rhythmical beats as gestures (images 11 and 14). Figure 4 is an interpretation that exemplifies the transition of higher-level actions in the excerpt.

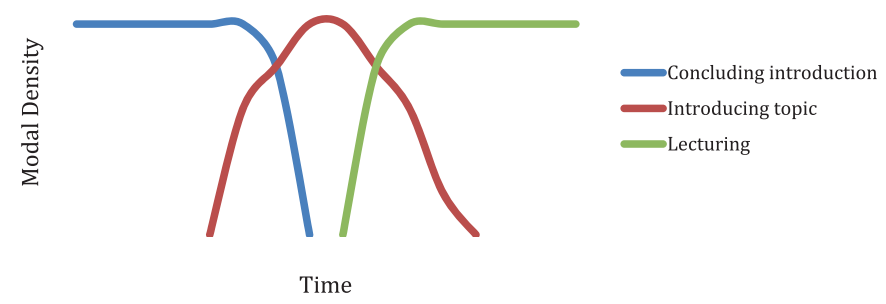

Figure 4: Higher-level actions' modal density across time in Excerpt 1.

\section{The role of metadiscourse in Excerpt 1}

The section between 08:23:15 and 08:29:20 (images 7 to 10) is explored when analyzing the role of metadiscourse to introduce topic with the following utterance:

- $\quad$ Give me two minutes to talk about the FEPC very quickly and move us into the 1940 .

While the lecturer is verbally introducing the topic through the use of metadiscourse, his gaze is directed towards the notes (images 7 and 8) with a one-second glance at the audience (image 9) and back to the notes (image 10) followed by a 1.5 seconds pause before he starts lecturing on the new topic. This seems to indicate that his focus is now on the notes preparing the upcoming lecturing on the FEPC. As discussed above, the higher-level action of introducing topic is highly influenced by the midgrounded action of lecturing. In this sense, introducing topic metadiscourse seems to be used as a pragmatic signal to communicate the change of topic to the audience. His focus on metadiscourse, as shown in Figure 4, is rather short and the higher-level action of lecturing takes over the foreground position in the continuum rather quickly. Thus, metadiscourse is used in this case merely to make the message more comprehensible to the listeners. Although this idea is consistent with most previous literature on metadiscourse, it is important to remark that the change of topic in the speaker's mind has already happened at a previous moment and that metadiscourse gives the impression of being irrelevant for the social actor whose focus is on the notes. The higher-level action of introducing topic (through the use of metadiscourse as a mediational means) is used as a "transitional action" between two modally denser higher-level actions. 


\section{Excerpt 2}

Excerpt 2 takes place 28 minutes into the lecture. Prof. Holloway finishes a note-driven part of the lecture and then concludes the topic through spontaneous comments. He then introduces the topic of "The legal history of the period" through the use of metadiscourse (28:42:25 to 29:00:06) while arranging the notes for the following section. Next, he starts lecturing on the new topic. Transcript 2 shows the mode of spoken language of the excerpt.

\section{Transcript 2: introducing topic "The legal history"}

28:35:25 now that's what's happening on sort of the high political

28:38:22 stage

28:42:25 throughout the 1940s. 7

\section{let me}

quickly

canvas what's happening

28:47:28 it's still politics of course but in the legal arena

28:51:22 over this period to help you understand

28:54:01 um an-another element of this of this shift that's happening in the country on these issues

29:00:06 and what I wanna give you is the legal history of Brown v. Board of Education

29:03:23 that's where this is heading up to

29:07:00 the legal history

29:10:00 begins

29:11:23 at Harvard University Law School
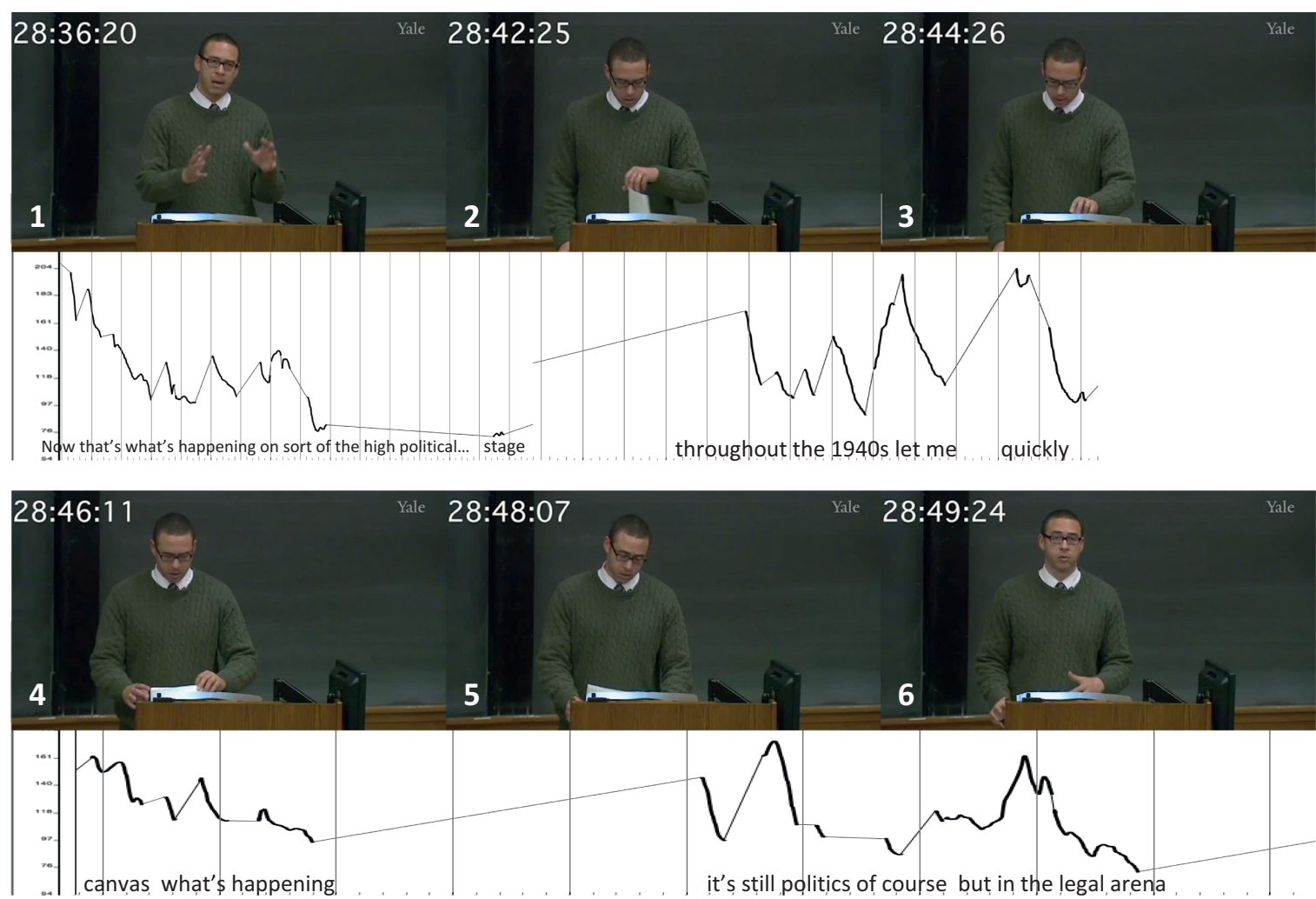

Figure 5: (a) Multimodal transcription of Excerpt 2. 

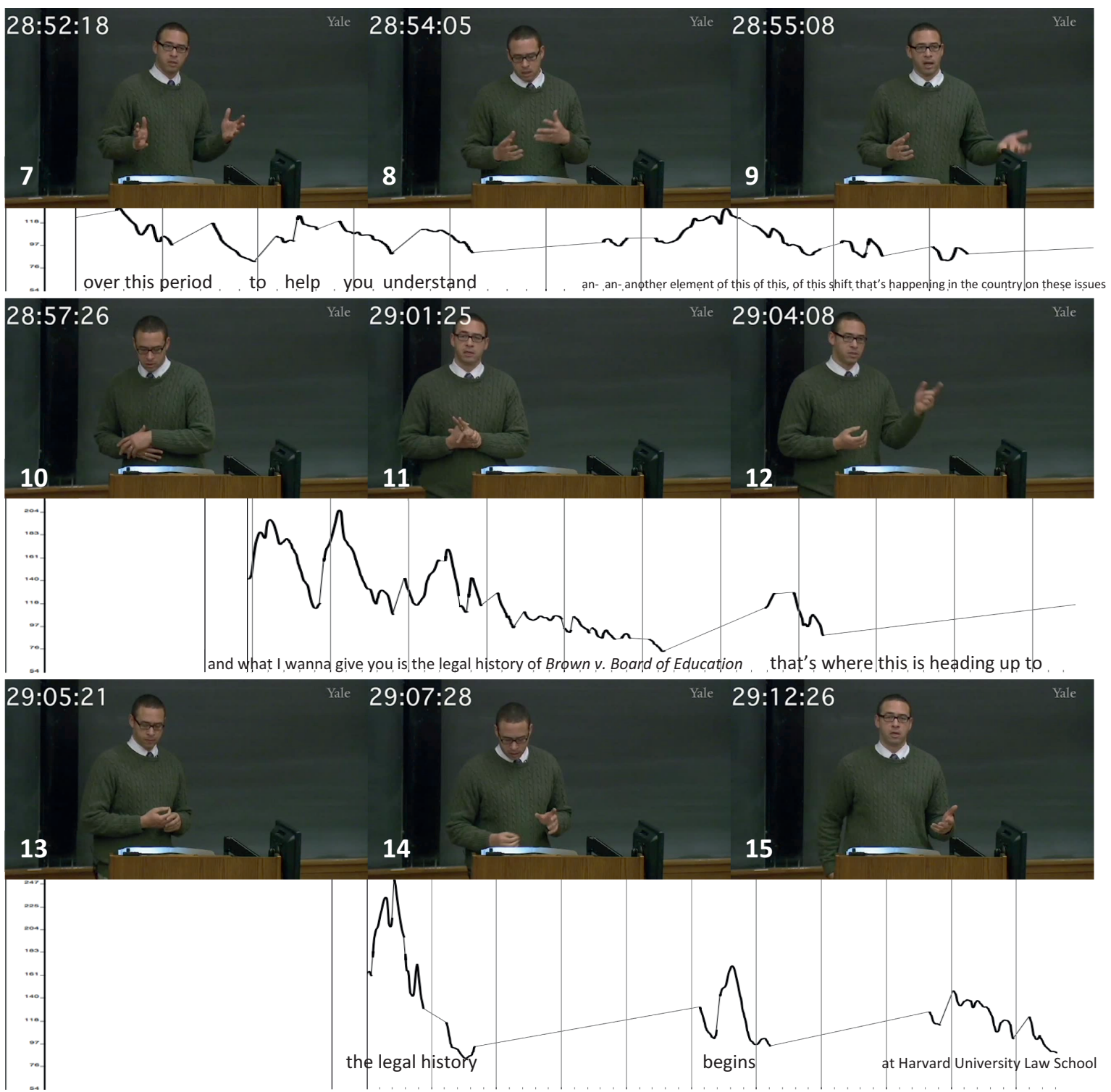

Figure 5: (b) Multimodal transcription of Excerpt 2.

Figure 5 shows a multimodal transcription of this excerpt. It begins at the end of the concluding section of the topic that I will refer to as "The political history". Prof. Holloway states "Now, that's what's happening on sort of the high political..." and accompanies the utterance with a metaphoric gesture performed with both hands that seems to express the uncertainty of the utterance. At the same time, he also performs a slight swaying movement. Then, he turns his gaze and body towards his notes, moves his right hand to the lectern and his left hand to the notes and finalizes the previous sentence by saying "stage". His falling intonation indicates the end of the utterance (image 1). At this point, he pauses for 3 seconds while handling his notes and then, he rushes through the sentence "throughout the 1940s" with a decreasing intonation that seems to indicate the completion of the previous utterance (image 2). Right after this utterance, the lecturer produces "let me...", pauses, continues by uttering "quickly", and produces another short pause while still organizing his notes (image 3). He continues "canvas what's happening" followed by another pause while handling the notes now with both hands (image 4). Prof. Holloway slightly tilts his head to his left and comments "it's still politics of course" and seems to have finished organizing his notes (image 5). 
After that, he places his right hand on the lectern, maintains his left hand in a holding position and turns his gaze and body to the audience while he carries out a slight leaning movement on the lectern. He then says "but in the legal arena" (image 6). Next, he slightly moves from right to left and produces the sentences "over this period" and "to help you understand" separated by a small pause and accompanied by a metaphoric gesture that consists of the movement of both hands in small circles (image 7). He produces a short glance to the notes and starts a slight swaying. He is still moving his hands while he hesitates "an-an-" (image 8). Then, he stops swaying and shifts his gaze back to the audience while saying "another element of this, of this shift that's happening in the country on these issues". He also moves his left hand from a central position to his left (image 9). He pauses for two seconds and leans on his notes while gazing at them. Moreover, he holds his hands together, swallows and licks his lips. Then, he begins "and what I wanna...." (image 10). Subsequently, he moves his body to an upright position and looks at the audience while saying “...give you is the legal history of Brown v. Board of Education" with a falling intonation and rising two fingers from his left hand while holding both of them together (image 11).

Next, he adds to his previous utterance by saying "that is where this is heading up to" in a falling intonation that indicates the end of the fragment. While producing the sentence, Prof. Holloway also performs a slight swaying and a deictic gesture with his left hand that seems to point to the abstract place referred to verbally (image 12). Then, he holds both of his hands together again while playing with his ring in silence (image 13). Finally, he shifts his gaze and body posture towards his notes and begins lecturing on the new topic "the legal history...". At this point, he produces a small pause while moving his right hand to the lectern and continues "begins..." also followed by a pause (image 14). He then turns his body and gaze towards the audience, places his right hand in his pocket, starts swaying and says "at Harvard University Law School..." with a rising intonation that indicates the presence of further information. He also performs a beat with his left hand by turning his palm up (image 15).

The analysis of the transcript shows four different higher-level actions (concluding topic, arranging notes, introducing topic and lecturing), as well as six different configurations in the attention/awareness shown by the lecturer that can be seen in Figures 6-8.

Figure 6 shows the first shift in foregrounded higher-level actions. The excerpt begins with Prof. Holloway focusing on the higher-level action of concluding the topic (Image 1). Graph 5 shows the modal density of this higher-level action, where posture, gaze, spoken language and gestures play an important role. As shown above in Image 1, the lecturer's focus is now on the audience and this can be seen in the configuration of his posture and gaze towards the listeners as well as the production of clear and uninterrupted spoken language. In addition, the gesture performed by the lecturer is a metaphorical one, which seems to offer a greater contribution to the message conveyed verbally than a beat would. The end of the utterance ("...stage") is marked by a falling intonation indicating the end of the verbal message, which hints the end of the present section.

At this point there is a shift in the attention/awareness towards higher-level actions. Prof. Holloway turns his gaze to his notes and lowers his right arm to the lectern in what seems to be a semantic/pragmatic means (Image 2). This gesture is a pronounced lower-level action that cannot be assigned to any of the higher-level actions involved (concluding topic or arranging notes). Instead, the semantic/pragmatic means is used by the lecturer as a structuring device of his actions. At that moment, he leans his body towards the lectern, which translates into a gradual increase in the modal density of the higher-level action of arranging notes. As a result, the higher-level action of arranging notes moves to the focus at this point (Graph 6).

The lecturer's gaze is now focused on his notes and all hand movements are devoted to the process of organizing notes (Images 2 to 5). Nevertheless, this shift in attention/awareness is not a clear boundary between one higher-level action and the next. Instead, the shift occurs gradually (see Figure 5). Right before performing the semantic/pragmatic means, the lecturer turns his gaze to his notes, which indicates the appearance of the higher-level action of arranging notes in the midground. More evidently, after the attention/awareness is shifted and the higher-level action of arranging notes is foregrounded, Prof. Holloway utters the sentence “...throughout the 1940s" with a very short syllabic duration and a falling 
Modal

density

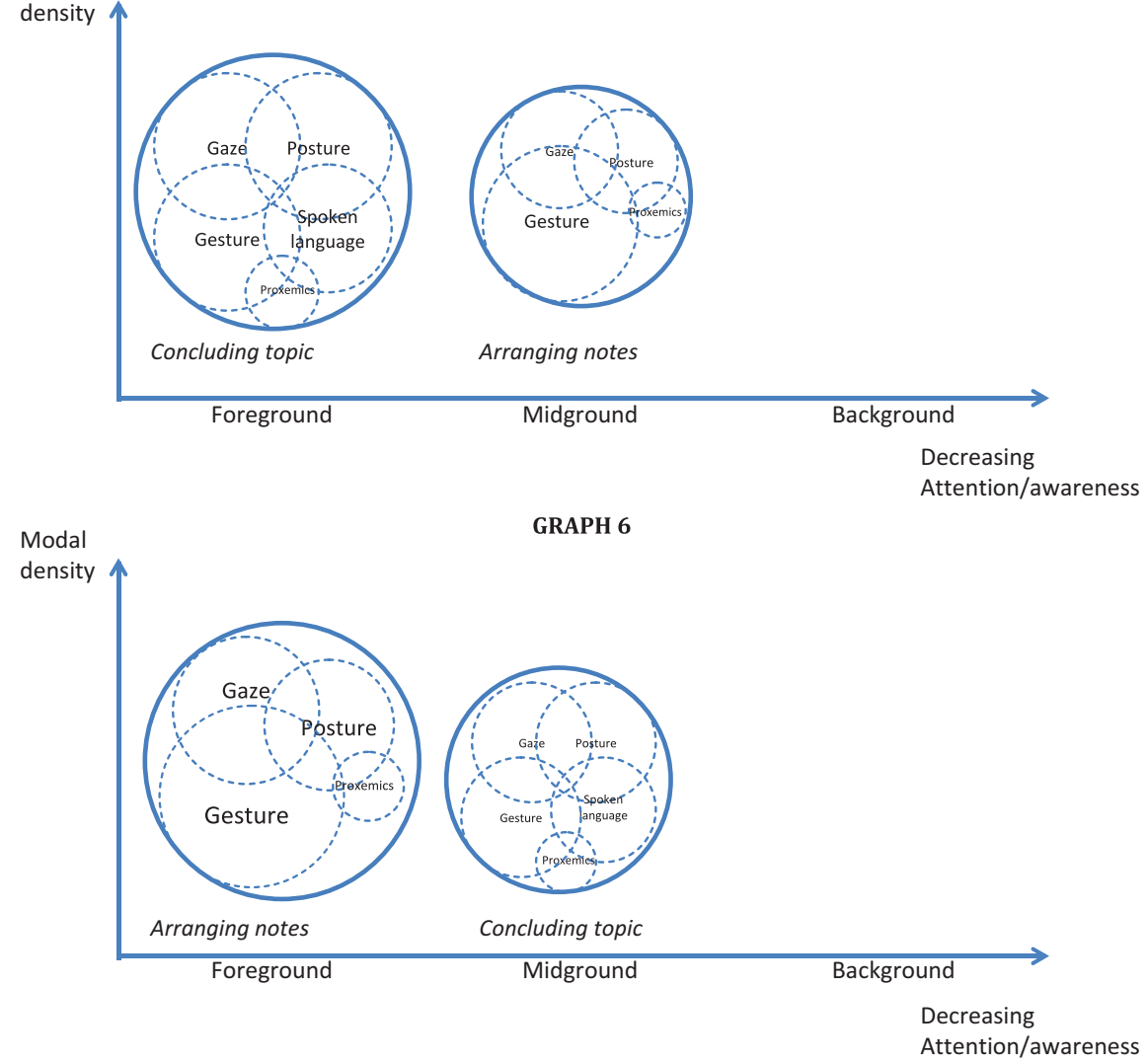

GRAPH 5

Figure 6: Shift in attention/awareness from concluding topic to arranging notes.

intonation. The content of the verbal message as well as the intonation in which it is produced indicates that the utterance belongs to the previous higher-level action still in the midground.

Right after this utterance, a new higher-level action becomes visible in the foreground/background continuum: introducing topic. In turn, concluding topic disappears as shown in Figure 7. The higher-level action of introducing-topic is here present in the midground (Graph 7). Although the mode of spoken language is exclusively devoted to introducing the new topic, the lecturer's gaze, posture and gestures are completely focused on his notes. This higher modal density shown in the higher-level action of arranging notes demonstrates that it is precisely this action that is focused on by the lecturer. Furthermore, the following utterances "Let me", "quickly" and "canvas what's happening" are performed in a slow manner and with relevant pauses in between. This use of intonation reinforces the idea that the mode of spoken language is devoted to a midgrounded action while the lecturer focuses on arranging his notes.

The higher-level action of introducing the topic is foregrounded later in the excerpt. After saying "it's still politics of course", Prof. Holloway turns his gaze and posture towards the audience. The spoken language mode is now more fluent with shorter or non-existent pauses. He has also finished arranging the notes and he performs two metaphorical gestures (Images 7 to 9). Graph 8 shows the shift in focus carried out by the speaker. The modal density of the higher-level action of introducing topic increases as the lecturer shifts his attention towards the audience. The higher-level action of arranging notes seems to vanish immediately in this case. 


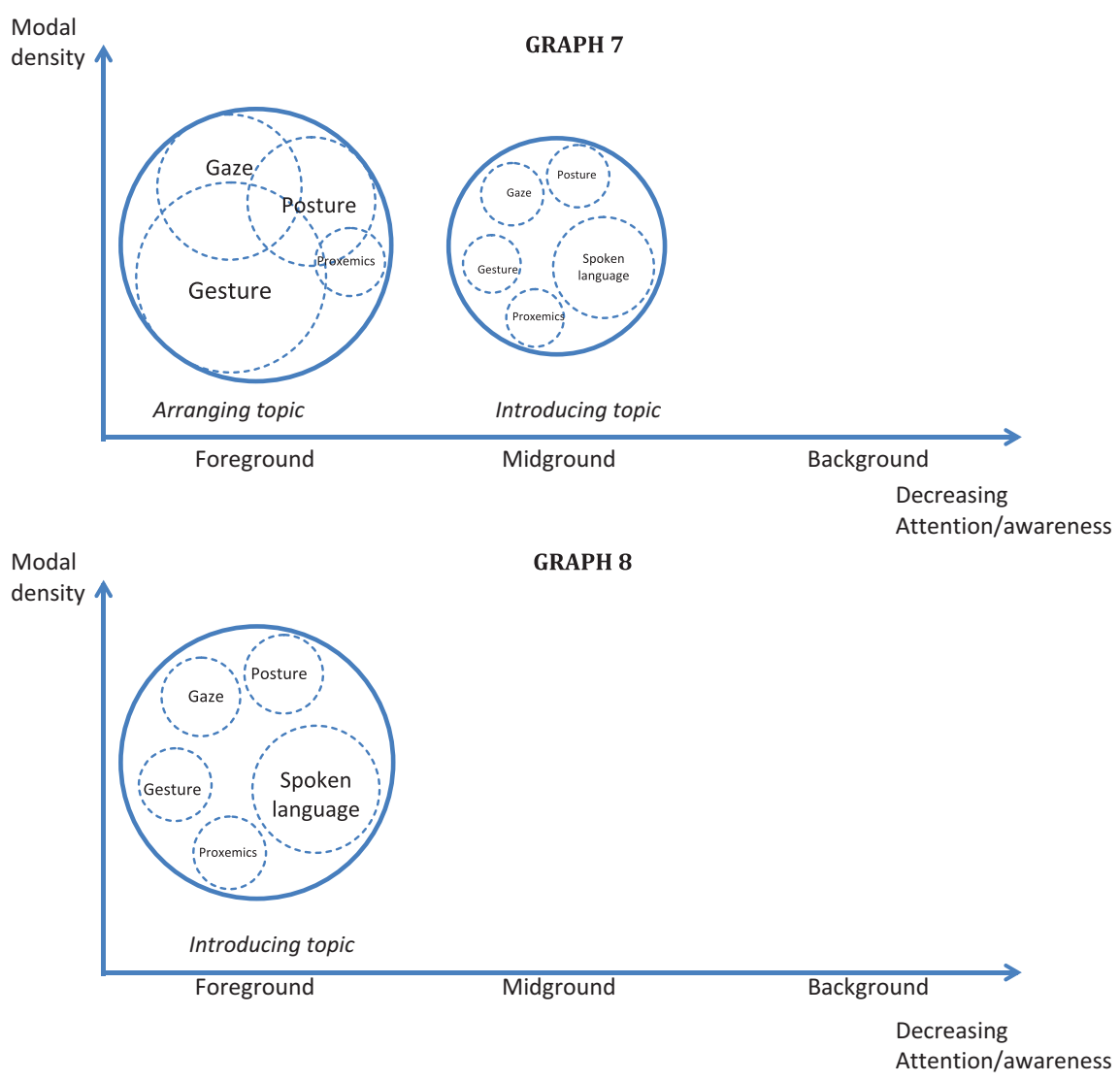

Figure 7: Shift in attention/awareness from arranging notes to introducing topic.

Some seconds later and after the utterance "that's happening in the country on these issues", the lecturer performs another semantic/pragmatic means (Image 10). He rubs his hands while pausing for a second, swallows and licks his lips. At this point, he looks at his notes for five seconds before verbally continuing with the introduction of the topic "and what I wanna give you...". His gaze turned to the notes as well as the long pause he makes seem to indicate the preparation of the next higher-level action, i.e. lecturing (Figure 8). Here, lecturing is midgrounded with a low modal density only shown through a higher relevance of the mode gaze (Graph 9) as the lecturer occasionally turns his gaze to the audience. Then, the lecturer turns his gaze to the audience once again and completes his introduction to the topic. Afterwards, he pauses for two seconds while looking at his notes once again and leaning towards the lectern (Images 13 and 14). At the end of the excerpt, the lecturer starts performing a series of patterns which are common to the higher-level action of lecturing mentioned earlier (Image 15). His higher-level action of lecturing relies heavily on his notes as a mediational means at this point, as his gaze shifts constantly from audience to notes and vice versa. He performs sequences of slight swaying that seem to mark an underlying rhythm to the lecture. The rising intonation of his last utterance ("at Harvard University Law School") indicates the arrival of new information.

Right away, the higher-level action of lecturing is completely foregrounded and introducing topic has already disappeared (Graph 10). Figure 9, again, exemplifies the transition of higher-level actions in the excerpt. 


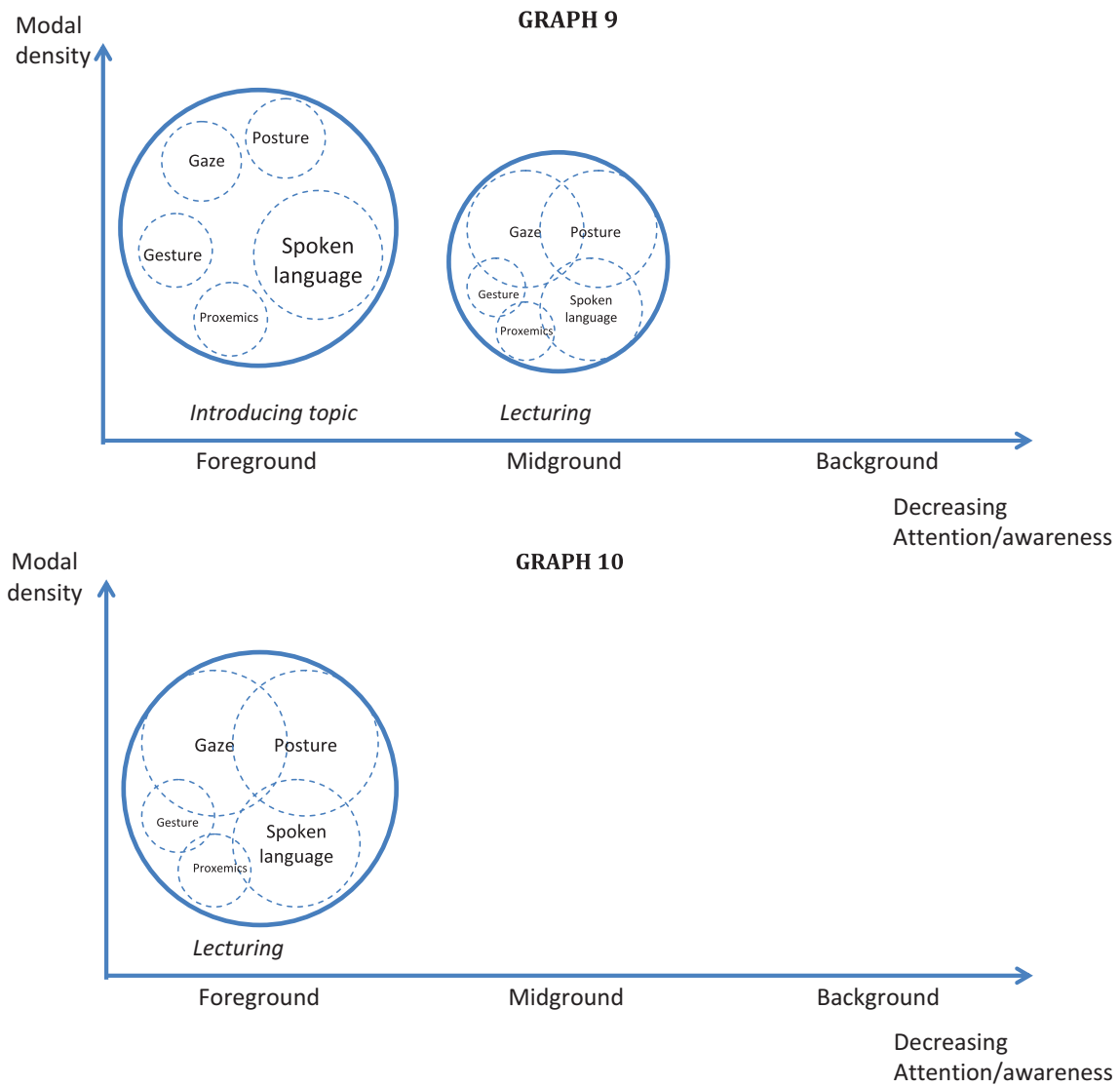

Figure 8: Shift in attention/awareness from introducing topic to lecturing.

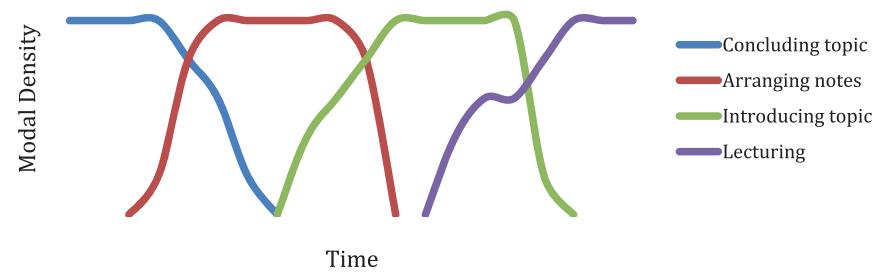

Figure 9: Higher-level actions' modal density across time in Excerpt 2.

\section{The role of metadiscourse in Excerpt 2}

The section between 28:44:26 and 29:01:25 (Images 3 to 12) includes two instances of introducing topic metadiscourse:

The role of metadiscourse in this excerpt

The role of metadiscourse in this excerpt

- Let me quickly canvas what's happening, it's still politics of course, but in the legal arena.

- And what I wanna give you is the legal history of Brown v. Board of Education. 
The first utterance introduces the new topic properly, as this represents the first moment when Prof. Holloway talks about the legal history. The second sentence specifies the first one by introducing Brown v. Board of Education.

Sentence 1 is verbally introduced while the lecturer's focus remains on the higher-level action of arranging notes (Images 3 to 5). His gaze, posture and hand-arm movements compose a highly dense multimodal ensemble demonstrating a higher level of attention/awareness towards arranging notes (see Graph 7). Introducing topic, on the other hand, is a midgrounded higher-level action that seems to be performed only through the spoken language mode. In addition, when the lecturer says "let me", "quickly" and "canvas what's happening" when introducing the new topic, he makes a short pause after each of these utterances, which seems to indicate a lack of attention towards the verbal mode as a midgrounded action. In this section, the lecturer appears to be preparing his notes for an upcoming event while metadiscourse is used only through the spoken language mode and as a background (midgrounded) task.

After this first metadiscursive sentence Prof. Holloway states what he is trying to accomplish by lecturing on this topic ("over this period, to help you understand an-an-another element of this, of this shift that's happening in the country on these issues"). This statement seems to be governed by a more spontaneous attitude. At this point in time the higher-level action of introducing topic is foregrounded (Graph 8). This is shown through a higher modal density towards the higher-level action of introducing topic where gaze and posture are focused on the audience, gestures become metaphorical thus gaining relevance in the conveyance of meaning, and the spoken language mode appears to be more fluent (Images 6 to 9).

Introducing topic stays foregrounded until the shift in attention/awareness to lecturing occurs towards the end of the excerpt. Nevertheless, the higher-level action of lecturing suddenly appears in the midground of the foreground/background continuum at an earlier moment, right before Prof. Holloway begins introducing the second part of his metadiscursive fragment (Graph 9, Image 9). This is shown through a shift in gaze and posture towards the notes and through a pause between the previous spontaneous comment and the utterance "and what I wanna give you...". The shift is only momentary and the higher-level action of introducing topic proceeds in the form of a non-note-driven spontaneous comment in the foreground. Still and all, it can be argued that lecturing is already in the midground and will become foregrounded at the end of the excerpt (Images 14 and 15).

All in all, metadiscourse gives the impression of being circumstantial in this excerpt. The lecturer organizes and structures the lecture through the higher-level actions of arranging notes and lecturing, which are note-driven. Metadiscourse is in Sentence 1 distinctly midgrounded while the lecturer is preparing notes for lecturing. The utterance of the metadiscursive sentence seems to be necessary for the lecturer, though, in an attempt to clarify the progress of the lecture. Metadiscourse in Sentence 2 is foregrounded in the higherlevel action of introducing topic together with a midgrounded lecturing higher-level action. Based on the analysis, I argue that the whole higher-level action of introducing topic is mostly midgrounded with its last part coming about in the foreground. Metadiscourse here appears to be functioning as a transition between the concluding higher-level actions of concluding the topic and the higher-level action of lecturing as well as serving the lecturer as a resource to maintain the conversation with the audience while preparing future sections of the lecture.

\section{Conclusion}

In this paper I have shown a small-scale study belonging to a larger project where I explore the use of organizational metadiscourse in academic lectures. In particular, I have examined two excerpts from a lecture where new topics are introduced. The main aim for this study was to explore the structure and 
organization of a lecture by looking at how topics are introduced and what role metadiscourse plays in these introductions.

A multimodal analysis based on the modes of spoken language (and its intonation), gesture, posture and gaze has provided a deeper insight into academic lecturing. The analyses have shown the structuring of lectures into varied higher-level actions performed by the lecturer, which include concluding sections, introducing topics, arranging notes and lecturing among them. Shifts between higher-level actions are usually marked by semantic/pragmatic means which carry out the semantic function for the lecturer of internally organizing his discourse and actions. Boundaries between higherlevel actions are not always clear-cut and sometimes midgrounded higher-level actions interfere in the foregrounded higher-level action both before and after a shift. In Excerpt 2 this stands out in the higher-level actions of arranging notes (influenced by concluding topic and introducing topic) and introducing topic (influenced by lecturing). This progressive fading in and out of higher-level actions has also been identified by Norris (2016).

Metadiscourse is used in both excerpts to verbally introduce the new topics. Nevertheless, what seems to be a clear structuring function is not so clear when analyzing the lecturer's actions holistically. Although in both excerpts metadiscourse is used as some sort of transitional higher-level action (introducing topic) that helps the lecturer move from one lecturing section to the other, its modal density is rather low if compared with the denser neighboring higher-level actions (concluding introduction/topic, lecturing). In the case of Excerpt 1 metadiscourse seems to have the function of letting the students know where the class is heading. However, the lecturer focuses mostly on his notes and introducing topic is only foregrounded for a short period of time. In Excerpt 2, metadiscourse partly serves as a tool to keep the verbal explanation going while the lecturer organizes his notes in preparation for lecturing.

Moreover, Prof. Holloway seems to perform two broad types of interaction: note-driven and spontaneous ones. From a multimodal perspective, note-driven interactions are characterized by a focus of gaze and posture on the notes, beat gestures, paused speech and occasional swaying. Spontaneous interactions are marked by a focus on the audience as well as fluent speech and occasional deictic and metaphoric gestures. The notes as a mediational means seem to constrain and define the type of interaction carried out by the lecturer. A multimodal analysis shows that a note-driven lecturing system constantly prevails over spontaneous teaching, thus making notes essential in the lecturer's interaction. The length of spontaneous higher-level actions where metadiscourse is used (like introducing topic) is usually very short and these actions become midgrounded most of the time (Figures 4 and 9).

Finally, I argue that metadiscourse is circumstantial in the process of organizing the lecture, i. e. it does not play a central role within the set of actions carried out by the social actor. Instead, the lecturer seems to organize his interaction through the use of semantic/pragmatic means that indicate shifts from one higherlevel action to another. Metadiscourse, albeit spontaneous and not note-driven, is most of the time performed as a mostly midgrounded higher-level action which is only foregrounded for short periods of time. It is used to let the audience know about the structure of the lecture (Excerpt 1) or as a tool to fill in the verbal mode while carrying out other actions (Excerpt 2).

\section{Limitations of the study and further research}

The present study is a small-scale approach based on two excerpts from a single lecture. Although these excerpts aim at being representative of the ways in which Prof. Holloway as a social actor introduces topics along the specific lecture being studied, the findings of the study cannot be generalized to other lecturers. The lecturer's personal traits and idiosyncratic style of lecturing shape in all likelihood the manner in which he structures the higher-level actions that he performs, and consequently, this structuring could be different in other conversational style lecturers. Nonetheless, this paper can be a 
reference and a starting point for similar studies that look into multimodal metadiscourse in academic settings.

In the larger-scale project where this study is encompassed six lecturers in six different lectures within humanities are analyzed from a multimodal point of view. Additional research at a larger scale on how, not only different conversational style lecturers, but also rhetorical and reading style lecturers use metadiscourse and introduce topics is needed to explore further the use of metadiscourse in academic lectures. Such investigation might provide more comprehensive results that could be applicable to new lecturers teaching training as it could outline advantages and problems to distinct lecturing approaches.

Acknowledgements: This paper has been possible thanks to the funding of Universitat Jaume I through two scholarships (ref: PREDOC/2013/49 and E-2016-12) and the project ref: P1·1B2015-72. I am also thankful to Dr. Jesse Pirini for his comments during the process of writing of this article. Finally, thank you to Prof. John Holloway and the opencourseware Open Yale Courses (oyc.yale.edu) from which the data were extracted.

Funding: Universitat Jaume I, (Grant/Award Number: ‘E-2016-12', ‘P1·1B2015-72’, ‘PREDOC/2013/49’).

\section{References}

Ädel, A. (2005). On the boundaries between evaluation and metadiscourse. In: Strategies in Academic Discourse, E. Tognini-Bonelli and G. Dell Lungo Camiciotti (Eds.), 153-162. Amsterdam \& Philadelphia: John Benjamins.

Ädel, A. (2006). Metadiscourse in L1 and L2 English. Amsterdam \& Philadelphia: John Benjamins.

Ädel, A. (2010). Just to give you kind of a map of where we are going: A taxonomy of metadiscourse in spoken and written academic English. Nordic Journal of English Studies, 9(2):69-97.

Ädel, A., and Mauranen, A. (2010). Metadiscourse: diverse and divided perspectives. Nordic Journal of English Studies, $9(2): 1-11$.

Bannink, A., and Van Dam, J. (2013). The first lecture: playing upon identities and modeling academic roles. Linguistics and Education, 24(4):556-571.

Bernad-Mechó, E., and Fortanet-Gómez, I. (2017). Semiotic modes in the organization of lectures in English and in Spanish. In: Professional and Academic Discourse: An Interdisciplinary Perspective (Epic Series in Language and Linguistics, Volume 2), C. Vargas-Sierra (Ed.), 224-234. http://easychair.org/publications/volume/AESLA_2016.

Cannam, C., Landone, C., and Sandler, M. (2010). Sonic visualiser: an open source application for viewing, analysing, and annotating music audio files. In MM '10. Proceedings of the 18th ACM International Conference on Multimedia. Firenze, Italy - October 25-29, 2010, 1467-1468. New York, NY: ACM.

Crawford-Camiciottoli, B. (2004). Interactive discourse structuring in L2 guest lectures: Some insights from a comparative corpus-based study. Journal of English for Academic Purposes, 3:39-54.

Crawford-Camiciottoli, B., and Fortanet-Gómez, I. (2015). Multimodal Analysis in Academic Settings: From Research to Teaching. New York \& London: Routledge.

Crismore, A., Markkanen, R., and Steffensen, M. (1993). Metadiscourse in persuasive writing: a study of texts written by American and Finnish university students. Written Communication, 10:39-71.

Dudley-Evans, T. (1994). Variations in the discourse patterns favoured by different disciplines and their pedagogical implications. In: Academic Listening: Research Perspectives, J. Flowerdew (Ed.), 146-158. Cambridge: Cambridge University Press.

Duff, P.A. (2010). Language socialization into academic discourse communities. Annual Review of Applied Linguistics, 30(1):169-192.

Fortanet-Gómez, I., and Ruiz-Madrid, M.N. (2015). Multimodal humour in plenary lectures in English and in Spanish. In: Multimodal Analysis in Academic Settings: From Research to Teaching, B. Crawford-Camiciottoli and I. Fortanet-Gómez (Eds.), 39-60. New York: Routledge.

Fortanet-Gómez, I., and Ruiz-Madrid, M.N. (2016). Multimodal humor in plenary lectures in English and in Spanish. Multimodal Communication, 5(1):55-69.

Fox, J., and Artemeva, N. (2013). The cinematic art of teaching university mathematics: Chalk talk as embodied practice.

Multimodal Communication, 1(1):83-103.

Halliday, M.A.K. (1973). Explorations in the functions of language. New York: Elsevier North-Holland, Inc.

Hyland, K. (2005). Metadiscourse: Exploring Interaction in Writing. London, England: Continuum. 
Hyland, K., and Tse, P. (2004). Metadiscourse in academic writing: a reappraisal. Applied Linguistics, 6(2):156-177. Jakobson, R. (1960). Closing statement: linguistics and poetics. In: Style in Language, T.A. Sebeok (Ed.), 350-377. Cambridge, Mass: M.I.T. Press.

Jakobson, R. (1998). On Language: Roman Jakobson. (L. R. Waugh \& M. Monville-Burston, Eds.). Cambridge, MA: Harvard University Press.

Lee, J.J., and Subtirelu, N.C. (2015). Metadiscourse in the classroom: A comparative analysis of EAP lessons and university lectures. English for Specific Purposes, 37:52-62.

Mao, L.M. (1993). “I conclude not”: toward a pragmatic account of metadiscourse. Rhetoric Review, 11(2):265-289.

Mauch, M., Cannam, C., Bittner, R., Fazekas, G., Salamon, J., Dai, J., ... Dixon, S. (2015). Computer-aided melody note transcription using the tony software: accuracy and efficiency. In: Proceedings of the 1st International Conference on Technologies for Music Notation and Representation (TENOR 2015), 25-30.

Mauch, M., and Dixon, S. (2014). pYin: a fundamental frequency estimator using probabilistic threshold distributions. In: 2014 IEEE International Conference on Acoustics, Speech and Signal Processing (ICASSP), 659-663. May 4-9, Florence, Italy.

Mauranen, A. (1993a). Contrastive ESP rhetoric: metatext in finnish-English economics text. English for Specific Purposes, 12:3-22.

Mauranen, A. (1993b). Cultural Differences in Academic Rhetoric: A Textlinguistic Study. Frankfurt am Main: Peter Lang.

McKeachie, W., and Svinicki, M. (2013). Teaching Tips: Strategies, Research, and Theory for College and University Teachers. 14th Edition. Boston: Cengage Learning.

McNeill, D. (1992). Hand and Mind: What Gestures Reveal about Thought. Chicago \& London: The University of Chicago Press. Nilson, L.B. (2016). Teaching at Its Best: A Research-Based Resource for College Instructors. 4th Edition. New York: Jossey-Bass. Norris, S. (2004). Analyzing Multimodal Interaction. A Methodological Framework. New York: Routledge.

Norris, S. (2011). Indentity in (Inter)Action. Introducing Multimodal Interaction Analysis. Göttingen: De Gruyter Mouton.

Norris, S. (2013). What is a mode? Smell, olfactory perception, and the notion of mode in multimodal mediated theory. Multimodal Communication, 2(2):155-169.

Norris, S. (2016). Concepts in multimodal discourse analysis with examples from video conferencing. Yearbook of the Poznań Linguistic Meeting, 2:141-165.

Norris, S. (2017). Scales of action: an example of driving and car talk in Germany and North America. Text and Talk, 37(1):117-139.

Palmer Silveira, J.C. (2002). Defining structure in business presentations: Linguistic features. In: Proposals and Resources for the Development of Oral Communication Skills, M.C. Campoy and M.P. Safont (Eds.), 185-202. Castelló de la Plana: Universitat Jaume I.

Palmer Silveira, J.C. (2004). Delivery strategies in classroom lectures: organising the message. In: Current Trends in Intercultural, Cognitive and Social Pragmatics, P. Garcés Conejos, R. Gómez Morón, L. Fernández Amaya and M. Padilla Cruz (Eds.), 97-114. Sevilla: Editorial Kronos.

Ruiz-Madrid, M.N., and Fortanet-Gómez, I. (2015). Contrastive multimodal analysis: conference plenary lectures in English and in Spanish. In: Multimodal Analysis in Academic Settings: From Research to Teaching, B. Crawford-Camiciottoli and I. Fortanet-Gómez (Eds.), 39-60. New York: Routledge.

Ruiz-Madrid, M.N., and Fortanet-Gómez, I. (2016). A model for a multimodal analysis of asides in conference plenary lectures. E-Aesla, 2:157-168.

Scollon, R. (1998). Mediated Discourse as Social Interaction. London, New York: Longman.

Scollon, R. (2001). Mediated Discourse: The Nexus of Practice. London, New York: Longman.

Swales, J.M. (1990). Genre Analysis: English in Academic and Research Settings. Cambridge: CUP.

Thesen, L. (2016). The past in the present: modes, gaze and changing communicative practices in lectures. In: Multimodality in Higher Education, A. Archer and E.O. Breuer (Eds.), 31-52. Leiden, The Netherlands: Koninklijke Brill NV.

Thompson, S.E. (2003). Text-structuring metadiscourse, intonation and the signaling of organization in academic lectures. Journal of English for Academic Purposes, 2:5-20.

Vande Kopple, W.J. (1985). Some exploratory discourse on metadiscourse. College Composition and Communication, 36(1):82-93.

Young, L. (1990). Language as Behaviour, Language as Code. A Study of Academic English. Amsterdam \& Philadelphia: John Benjamins.

Young, L. (1994). University lectures - macro-structure and micro-features. In: Academic Listening: Research Perspectives, J. Flowerdew (Ed.), 159-176, Cambridge: Cambridge University Press. 